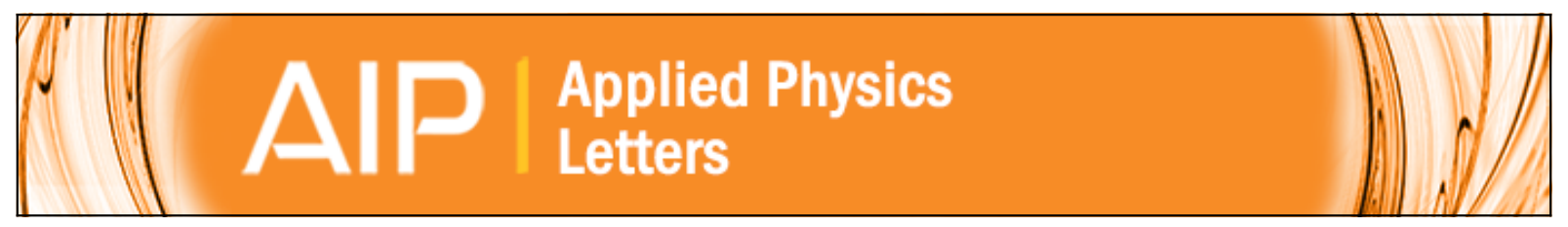

\title{
Ultrathin silicon oxynitride film formation by plasma immersion nitrogen implantation
}

I. J. R. Baumvol, C. Krug, F. C. Stedile, M. L. Green, D. C. Jacobson, D. Eaglesham, J. D. Bernstein, J. Shao, A.

S. Denholm, and P. L. Kellerman

Citation: Applied Physics Letters 74, 806 (1999); doi: 10.1063/1.123374

View online: http://dx.doi.org/10.1063/1.123374

View Table of Contents: http://scitation.aip.org/content/aip/journal/apl/74/6?ver=pdfcov

Published by the AIP Publishing

\section{Articles you may be interested in}

Tailored stoichiometries of silicon carbonitride thin films prepared by combined radio frequency magnetron sputtering and ion beam synthesis

J. Vac. Sci. Technol. A 23, 1114 (2005); 10.1116/1.1946713

Interface properties and reliability of ultrathin oxynitride films grown on strained Si 1-x Ge x substrates J. Appl. Phys. 93, 2464 (2003); 10.1063/1.1540224

Comparison of ultralow-energy ion implantation of boron and BF 2 for ultrashallow $p+/ n$ junction formation Appl. Phys. Lett. 74, 1248 (1999); 10.1063/1.123514

Incorporation of oxygen and nitrogen in ultrathin films of SiO 2 annealed in NO

Appl. Phys. Lett. 72, 2999 (1998); 10.1063/1.121520

Remote plasma chemical vapor deposition silicon oxynitride thin films: Dielectric properties

J. Vac. Sci. Technol. B 16, 1087 (1998); 10.1116/1.590013

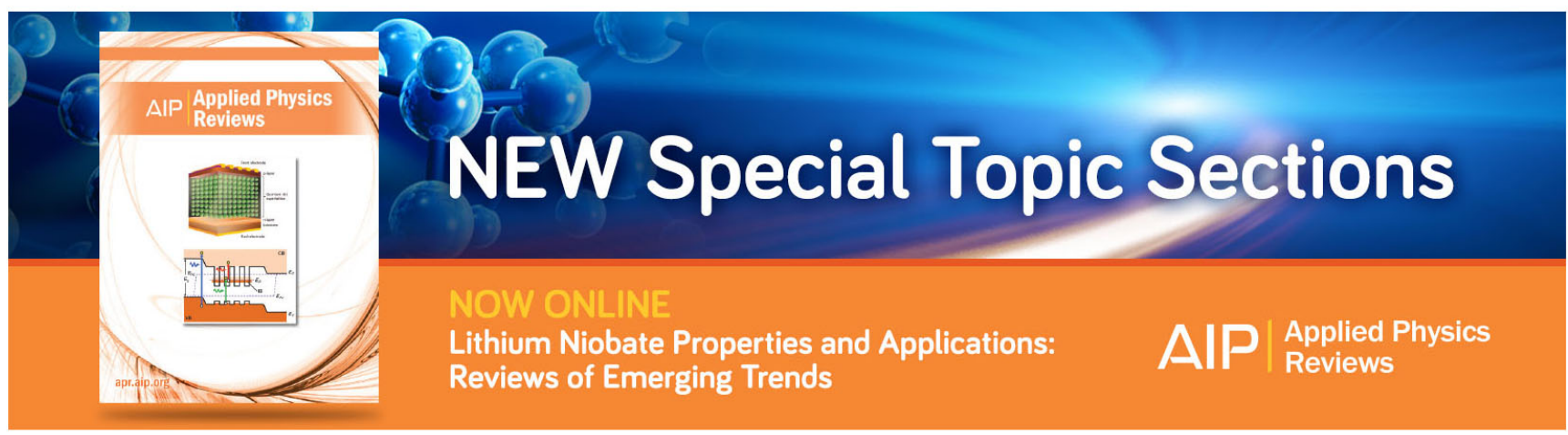




\title{
Ultrathin silicon oxynitride film formation by plasma immersion nitrogen implantation
}

\author{
I. J. R. Baumvol, ${ }^{\text {a) }}$ C. Krug, and F. C. Stedile \\ Instituto de Física-Instituto de Química, UFRGS, Porto Alegre, Rio Grande do Sul 91509-900, Brazil \\ M. L. Green, D. C. Jacobson, and D. Eaglesham \\ Bell Laboratories-Lucent Technologies, Murray Hill, New Jersey 07974
}

J. D. Bernstein, J. Shao, A. S. Denholm, and P. L. Kellerman

Eaton Corporation, Implant Systems Division, Beverly, Massachussets 01915

(Received 25 September 1998; accepted for publication 1 December 1998)

A method is proposed to prepare ultrathin silicon oxynitride films for gate dielectrics used in deep submicron metal-oxide-semiconductor field effect transistor device structures, namely plasma immersion $\mathrm{N}$ implantation into $\mathrm{SiO}_{2}$ films. Plasma immersion implantation pulse voltages in the range 200-1000 V, and fluences from $10^{16}$ to $10^{17} \mathrm{~N} \mathrm{~cm}^{-2}$ were implanted into thermally grown $\mathrm{SiO}_{2}$ films, with thicknesses between 3 and $6 \mathrm{~nm}$. The areal densities of $\mathrm{N}$ and $\mathrm{O}$ in the resulting oxynitride films were determined by nuclear reaction analysis, before and after annealing in high-vacuum. N, O, and $\mathrm{Si}$ profiles in the films were determined with subnanometric depth resolution by medium energy ion scattering. The results indicate that plasma immersion ion implantation allows for shallow and controlled deposition of significant amounts of nitrogen (up to $3.8 \mathrm{~nm}$ of equivalent $\mathrm{Si}_{3} \mathrm{~N}_{4}$ thickness). Implantation is accompanied by moderate damage at the oxynitride/Si interface which can be recovered by thermal annealing. (C) 1999 American Institute of Physics. [S0003-6951(99)01706-4]

Increasing attention has been devoted to ultrathin silicon oxynitride films for use as gate dielectrics in subquartermicron metal-oxide-semiconductor field effect (MOSFET) devices, from the viewpoint of performance and reliability. ${ }^{1,2}$ Ion implantation of nitrogen at low energies (between 10 and $1000 \mathrm{eV}$ ) is now being considered as an attractive, low temperature, and controllable route to form these materials, as compared to typical high thermal budget growths in $\mathrm{N}_{2} \mathrm{O}$ or $\mathrm{NO}^{3-7}$ Further, ion implantation can result in oxynitrides with higher $\mathrm{N}$ concentration than the aforementioned thermal processes.

We report here on studies of plasma immersion ion implantation (PIII) of $\mathrm{N}^{8,9}$ into bare $\mathrm{Si}$, or ultrathin $\mathrm{SiO}_{2}$ films (preoxides). The pulse voltage in the plasma immersion apparatus was varied between 200 and $1000 \mathrm{~V}$. According to the projected ranges and straggling obtained from Monte Carlo simulations using the TRIM program ${ }^{10}$ given in Table I, in this energy range a substantial amount of the implanted $\mathrm{N}$ atoms should remain within the oxide films. The implantation fluences were between $10^{16}$ and $10^{17} \mathrm{~N} \mathrm{~cm}^{-2}$. The areal densities of $\mathrm{N}$ and $\mathrm{O}$ in the films were determined by nuclear reaction analysis (NRA) using, respectively, the ${ }^{14} \mathrm{~N}\left(d, \alpha_{0}\right){ }^{13} \mathrm{C}$ reaction at $1.45 \mathrm{MeV}$, and the ${ }^{16} \mathrm{O}(d, p){ }^{17} \mathrm{O}$ reaction at $810 \mathrm{keV}$, and convenient standards. ${ }^{11}$ The depth profiles of $\mathrm{N}, \mathrm{O}$, and $\mathrm{Si}$ were determined with a depth resolution of approximately $0.5 \mathrm{~nm}$ by medium energy ion scattering (MEIS), using a $97.2 \mathrm{keV}$ proton beam and a doublechanneling geometry of the $\mathrm{Si}(100)$ substrates. ${ }^{12}$ Annealing of the implanted samples was performed by rapid thermal processing (RTP) at $925^{\circ} \mathrm{C}$, for $10 \mathrm{~s}$, in high vacuum.

${ }^{a)}$ Electronic mail: israel@if.ufrgs.br
Figure 1 shows the areal densities of $\mathrm{O}, \mathrm{N}$, and $\mathrm{O}+\mathrm{N}$ as a function of the preoxide thickness, for the three different PIII pulse voltages (200, 500 and $1000 \mathrm{~V})$, and the two different implantation doses: $10^{16} \mathrm{~N} \mathrm{~cm}^{-2}$ [Fig. 1(a)] and $10^{17} \mathrm{~N} \mathrm{~cm}^{-2}$ [Fig. 1(b)]. The $(\mathrm{O}+\mathrm{N})$ areal densities allow one to estimate the thicknesses of the resulting oxynitride films, derived from the bulk densities of $\mathrm{SiO}_{2}$ and $\mathrm{Si}_{3} \mathrm{~N}_{4}: \quad 10^{15} \mathrm{O}$ atoms cm $\mathrm{cm}^{-2}=0.226 \mathrm{~nm}$ of $\mathrm{SiO}_{2}, \quad$ and $10^{15} \mathrm{~N}$ atoms $\mathrm{cm}^{-2}=0.188 \mathrm{~nm}$ of $\mathrm{Si}_{3} \mathrm{~N}_{4}$.

$\mathrm{O}, \mathrm{N}$, and $\mathrm{Si}$ depth profiles for different implantation doses and energies into $3 \mathrm{~nm}$ thick preoxides are shown in Figs. 2 and 3. The increase of the Si signal at depths beyond the oxynitride/Si interfaces reveals amorphization of the $\mathrm{Si}(100)$ substrate region close to the interface due to $\mathrm{N}$ implantation. At greater depths, the Si signal decreases due to the channeling of the proton beam in the single crystalline lattice, as expected. Rapid thermal annealing of the implanted oxides in high vacuum results in epitaxial recrystallization of the amorphized region close to the oxynitride/Si interface, with only minor changes in the areal densities and depth distributions of $\mathrm{O}$ and $\mathrm{N}$ in the films. This is illustrated by the profiles in Fig. 4, corresponding to a $6 \mathrm{~nm}$ thick pre-

TABLE I. Calculated projected ranges and straggling of $\mathrm{N}$ ions implanted into ultrathin $\mathrm{SiO}_{2}$ films. Calculated sputtering rates of $\mathrm{Si}$ and $\mathrm{O}$ from these films due to $\mathrm{N}$ implantation are also shown.

\begin{tabular}{ccccc}
\hline \hline $\begin{array}{c}\text { Pulse } \\
\text { voltage (V) }\end{array}$ & $\begin{array}{c}\text { N projected } \\
\text { range (nm) }\end{array}$ & $\begin{array}{c}\text { straggling } \\
(\mathrm{nm})\end{array}$ & $\begin{array}{c}\text { Si sputtering rate } \\
\text { (atoms/incident } \\
\text { ion) }\end{array}$ & $\begin{array}{c}\text { O sputtering rate } \\
\text { (atoms/incident } \\
\text { ion) }\end{array}$ \\
\hline 200 & 1.6 & 0.8 & 0.01 & 0.03 \\
500 & 2.8 & 1.4 & 0.03 & 0.08 \\
1000 & 4.4 & 2.2 & 0.05 & 0.12 \\
\hline \hline
\end{tabular}



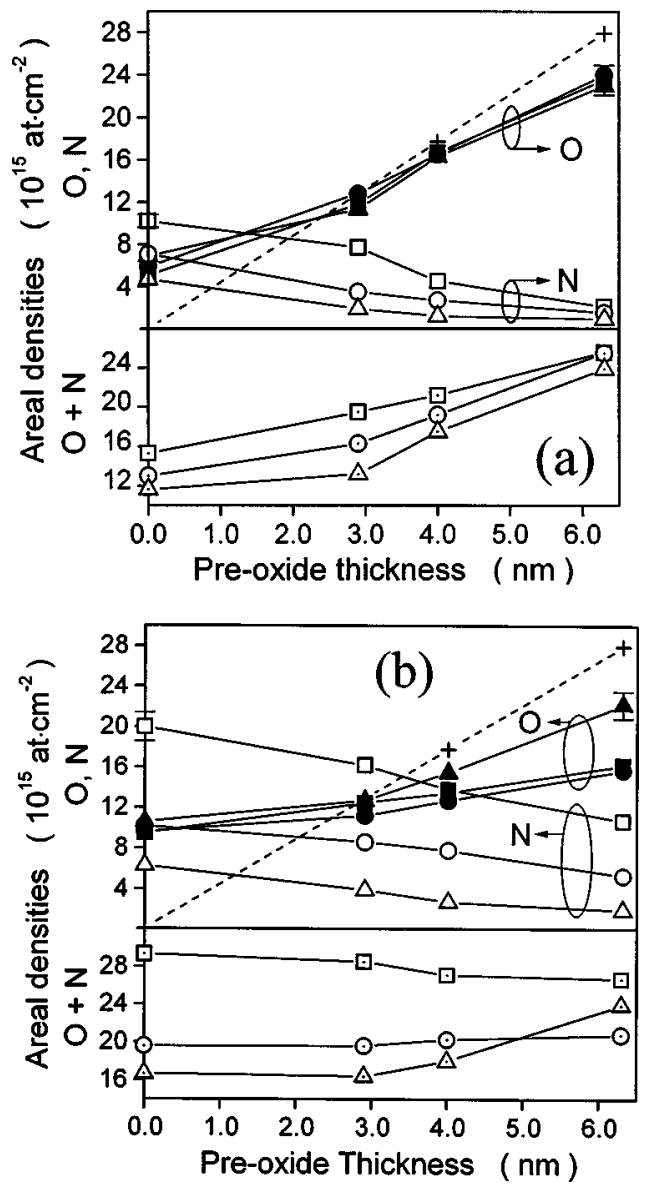

FIG. 1. Areal densities of $\mathrm{O}, \mathrm{N}$, and $(\mathrm{O}+\mathrm{N})$ as a function of the preoxide thickness, for three different plasma immersion implantation pulse voltages: $1000 \mathrm{~V}$ (squares), $500 \mathrm{~V}$ (circles), and $200 \mathrm{~V}$ (triangles). (a) $10^{16} \mathrm{~N} \mathrm{~cm}^{-2}$; and (b) $10^{17} \mathrm{~N} \mathrm{~cm}^{-2}$. The crosses and dashed lines represent the $\mathrm{O}$ content of the preoxide films.

oxide, implanted with $10^{17} \mathrm{~N} \mathrm{~cm}^{-2}$, and submitted to rapid thermal annealing in ultrahigh vacuum at $925^{\circ} \mathrm{C}$, for $10 \mathrm{~s}$.

Summarizing the results shown in Fig. 1, one notices that: (i) the amounts of $\mathrm{O}$ found in the oxynitride films after $\mathrm{N}$ implantation increase faster with increasing preoxide thickness for $10^{16}$ than for $10^{17} \mathrm{~N} \mathrm{~cm}^{-2}$ implants, and are independent of the implantation energies; and (ii) the sum of the areal densities of $\mathrm{O}$ and $\mathrm{N}$ (essentially the oxynitride film thicknesses) increase with increasing preoxide thickness for all $10^{16} \mathrm{~N} \mathrm{~cm}^{-2}$ implants and for the $10^{17} \mathrm{~N} \mathrm{~cm}^{-2}$ implants at $200 \mathrm{~V}$, whereas it remains practically constant for $10^{17} \mathrm{~N} \mathrm{~cm}^{-2}$ implants at 500 and $1000 \mathrm{~V}$. These two facts can be understood on the basis of the reasonably well known dependence of sputtering rate on the kinetic energy of incident $\mathrm{N}$ ions, as well as on the composition of the nearsurface layers of the implanted material. Table I indicates a preferential sputtering of $\mathrm{O}$, and overall sputtering rates between 0.04 and 0.17 atoms per incident ion. ${ }^{13}$ For $10^{16} \mathrm{~N} \mathrm{~cm}^{-2}$ implants this results in between 0.3 and 1.2 $\times 10^{15}$ sputtered $\mathrm{O}$ atoms $\mathrm{cm}^{-2}$, which represents a small fraction of the oxygen areal densities of the preoxides (e.g., approximately $1.4 \times 10^{16} \mathrm{O} \mathrm{cm}^{-2}$ in a $3 \mathrm{~nm}$ oxide film). Therefore, the preoxide thicknesses are not significantly altered by implantation. However, for $10^{17} \mathrm{~N} \mathrm{~cm}^{-2}$ implants, the total number of sputtered atoms should stay in the range $(0.3-1.2) \times 10^{16} \mathrm{O} \mathrm{cm}^{-2}$, comparable to the areal densities in

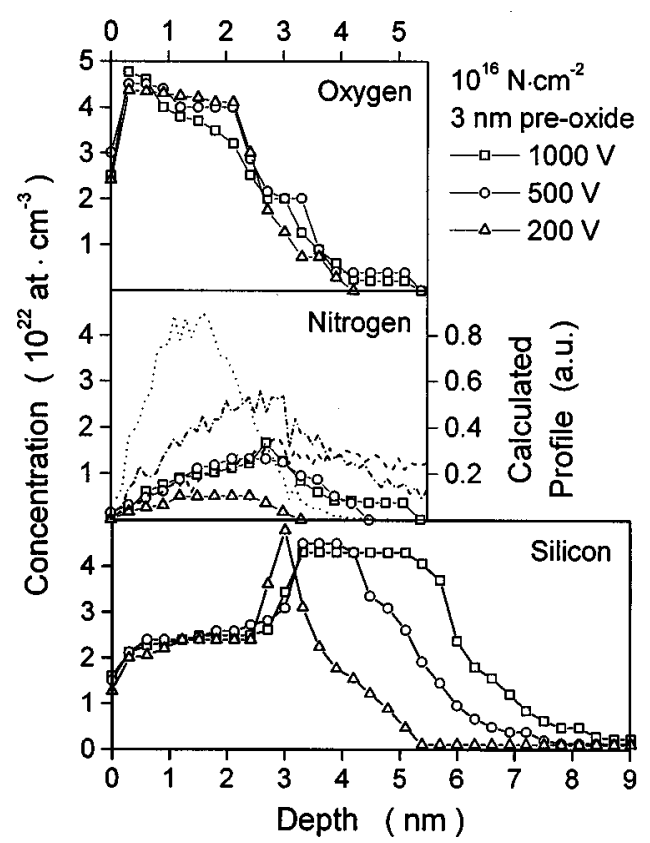

FIG. 2. O, N, and Si profiles as determined by medium energy ion scattering for $3 \mathrm{~nm}$ thick preoxides implanted with $10^{16} \mathrm{~N} \mathrm{~cm}^{-2}$ at three different pulse voltages: $200 \mathrm{~V}$ (triangles), $500 \mathrm{~V}$ (circles), and $1000 \mathrm{~V}$ (squares). The $\mathrm{N}$ depth profiles (right $y$ axis) as calculated by Monte Carlo simulations using the program Transport of Ions in Matter (TRIM) (Ref. 10) are also given for the three different pulse voltages: $200 \mathrm{~V}$ (dotted line), $500 \mathrm{~V}$ (dashed-dotted line), and $1000 \mathrm{~V}$ (dashed line).

the preoxide films. So, observations (i) and (ii) result from the competition among preoxide thickness, $\mathrm{N}$ implantation, and sputtering.

Other observations cannot be explained by the estimated effects of sputtering, e.g., (iii) the retained amounts of $\mathrm{N}$ increase with increasing implantation energy. Judging only from the energy dependence of the sputtering rates (Table I), one would expect the opposite. The explanation may come from another fact emerging from Fig. 1, namely (iv) the re-

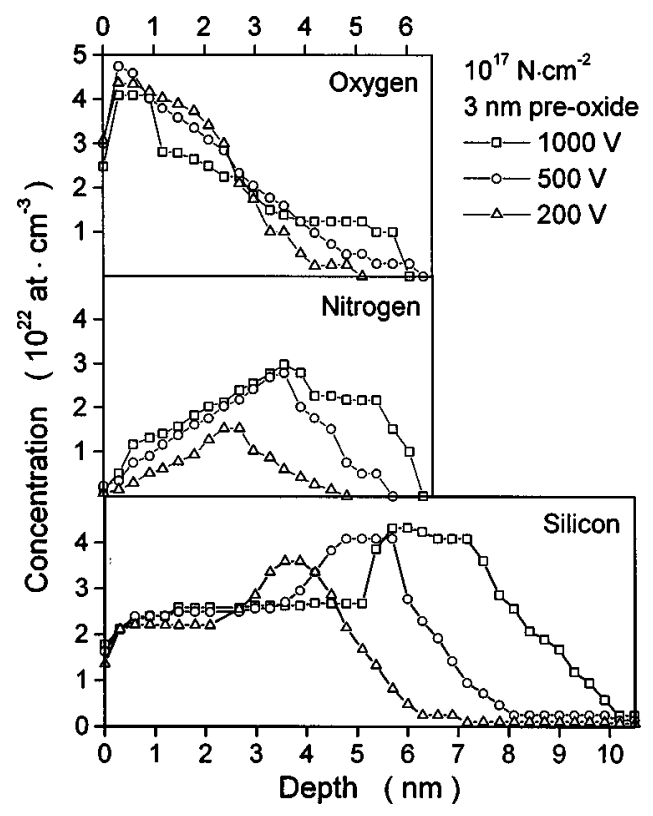

FIG. 3. O, N, and Si depth profiles for $3 \mathrm{~nm}$ thick preoxides implanted with $10^{17} \mathrm{~N} \mathrm{~cm}^{-2}$ at three different pulse voltages: $1000 \mathrm{~V}$ (squares), $500 \mathrm{~V}$ (circles), and $200 \mathrm{~V}$ (triangles). 


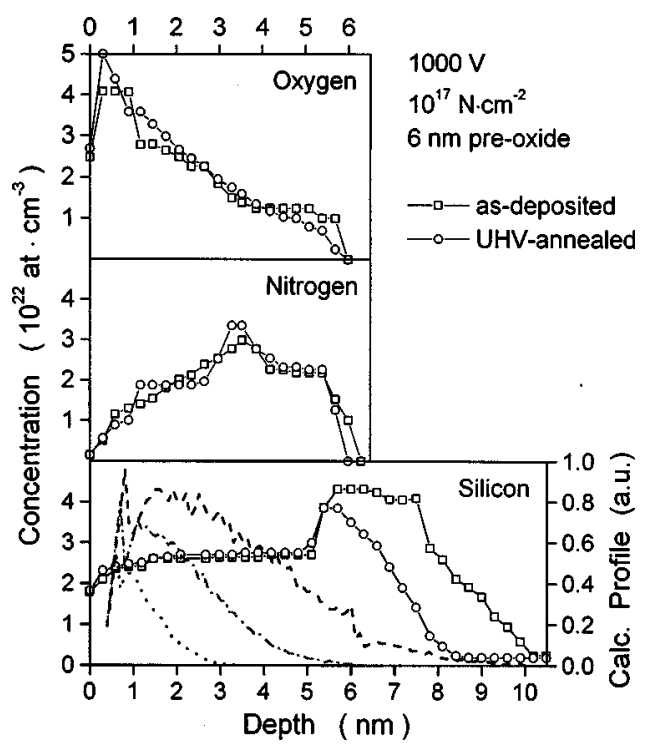

FIG. 4. O, N, and Si profiles for a $6 \mathrm{~nm}$ thick preoxide, implanted with $10^{17} \mathrm{~N} \mathrm{~cm}^{-2}$, before (squares) and after (circles) rapid thermal annealing in ultrahigh vacuum at $925^{\circ} \mathrm{C}$, for $10 \mathrm{~s}$. The vacancy profiles (right $y$ axis) obtained from Monte Carlo simulations using the TRIM program (Ref. 10) are represented for three different implantation pulse voltages: $200 \mathrm{~V}$ (dotted line), $500 \mathrm{~V}$ (dashed-dotted line), and $1000 \mathrm{~V}$ (dashed line).

tained amounts of $\mathrm{N}$ decrease with increasing preoxide thickness, for all the implantation energies and doses. Table I shows that as the thickness of the preoxide increases (or the implantation energy decreases), a larger fraction of the implanted $\mathrm{N}$ remains within the oxide film. However, the precursors for $\mathrm{N}$ incorporation into the silica network are not $\mathrm{N}$ or $\mathrm{N}_{2} \cdot{ }^{14-17}$ On the other hand, $\mathrm{N}$ reacts with $\mathrm{Si}$, forming stable (stoichiometric or nonstoichiometric) silicon nitrides. ${ }^{11}$ So, within the interval of implantation energies used in the present work, the retained amount of $\mathrm{N}$ should increase with the ratio between $\mathrm{N}$ atoms implanted into the $\mathrm{Si}$ substrate and into the $\mathrm{SiO}_{2}$ film. For example, in the case of $3 \mathrm{~nm}$ thick preoxides, these ratios can be estimated as $0.30,0.25$, and 0.03 for $10^{16} \mathrm{~N} \mathrm{~cm}^{-2}$ implants (Fig. 2), and as $0.50,0.40$, and 0.17 for $10^{17} \mathrm{~N} \mathrm{~cm}^{-2}$ implants (Fig. 3), for 1000,500 , and $200 \mathrm{~V}$, respectively. Although the sputtering rate increases with implantation energy in this range, the chemical effect dominates, and the retained amounts of $\mathrm{N}$ increase with increasing energy.

Figure 2 allows for a comparison between $\mathrm{N}$ depth distributions determined experimentally by MEIS, and calculated by Monte Carlo simulations using TRIM. One can see that these calculations can reasonably reproduce the observed profiles, even though the energy range of the present implants is in the lower limit of validity of TRIM. ${ }^{10}$ Since the profiles are not changed by thermal annealing (see Fig. 4), one can use TRIM results to simulate the final distribution of $\mathrm{O}$ and $\mathrm{N}$ in the oxynitride films.

Figure 4 also shows vacancy profiles obtained from Monte Carlo simulations, ${ }^{10}$ illustrating the potential of plasma implantation to control the damage to the Si sub- strate, as well as at the oxynitrite/Si interface. Indeed, in the case of a $6 \mathrm{~nm}$ preoxide, even the highest energy $(1000 \mathrm{~V})$ implants create most of the damage within the amorphous oxynitride film. By adjusting the preoxide thickness, implantation energy and dose, and thermal annealing conditions, one can obtain a tailored oxynitride film, with minimum level of damage at the interface and in the Si substrate.

In summary, we have implanted $\mathrm{N}$ ions in the PIII pulse voltage range from 200 to $1000 \mathrm{~V}$ into ultrathin $\mathrm{SiO}_{2} / \mathrm{Si}(100)$ films. The composition of the obtained silicon oxynitride films is determined by a competition between sputtering rates, preoxide thicknesses, ion ranges, and the chemistry of $\mathrm{N}$ incorporation into silica and bare silicon. The amorphization of the Si substrate due to $\mathrm{N}$ implantation can be reversed by rapid thermal annealing in vacuum without major redistribution of the chemical species in the oxynitride films. The $\mathrm{N}$ depth profiles can be reasonably well simulated by calculations based on Monte Carlo methods.

The authors thank Pedro Grande from Instituto de Física, Porto Alegre, for help with Monte Carlo simulations, and to M. Alam and G. Timp from Bell Laboratories/Lucent Technologies, and E. P. Gusev, E. L. Garfunkel, and H. C. Lu from Rutgers University for help with sample preparation and analyses.

${ }^{1}$ L. C. Feldman, E. P. Gusev, and E. Garfunkel, "Ultrathin dielectrics in silicon microelectronics-an overview" in Fundamental Aspects of Ultrathin Dielectrics on Si-based Devices, edited by E. Garfunkel, E. P. Gusev, and A. Vul' (Kluwer Academic, Dordrecht, 1998), p. 1.

${ }^{2} \mathrm{H}$. Fukuda, T. Endoh, and S. Nomura, "Characterization of the $\mathrm{SiO}_{2} / \mathrm{Si}$ Interface structure and the dielectric properties of $\mathrm{N}_{2} \mathrm{O}$-oxynitrided ultrathin $\mathrm{SiO}_{2}$ Films" in The Physics and Chemistry of $\mathrm{SiO}_{2}$ and the $\mathrm{Si} / \mathrm{SiO}$ Interface, edited by H. Z. Massoud, E. H. Poindexter, and C. R. Helms (The Electrochemical Society, Pennington, NJ, 1996), p. 15.

${ }^{3}$ C. Lin, A. I. Chou, P. Choudhry, J. Lee, K. Kumar, B. Doyle, and H. R. Soleimani, Appl. Phys. Lett. 69, 3701 (1996).

${ }^{4}$ T. Kuroi, M. Shirahata, Y. Okumura, S. Shimizu, A. Teramoto, M. Anma, M. Inuishi, and H. Miyoshi, Jpn. J. Appl. Phys., Part 1 35, 1454 (1996).

${ }^{5}$ H. R. Soleimani, B. S. Doyle, and A. Philipossian J. Electrochem. Soc. 142, L132 (1995).

${ }^{6}$ I. J. R. Baumvol, T. D. M. Salgado, C. Radtke, C. Krug, and F. C. Stedile, J. Appl. Phys. 83, 5579 (1998).

${ }^{7}$ R. Kraft, T. P. Schneider, W. W. Dostalik, and S. Hattangady, J. Vac. Sci. Technol. B 15, 967 (1997).

${ }^{8}$ J. W. Mantese, I. G. Brown, N. W. Cheung, and G. A. Collins, MRS Bull. 21, 52 (1997).

${ }^{9}$ S. Mändl, J. Brutscher, R. Gunzel, and W. Möller, J. Vac. Sci. Technol. B 14, 2701 (1997).

${ }^{10}$ J. P. Ziegler, J. P. Biersack, and U. Littmark, The Stopping and Range of Ions in Solids (Pergamon, New York, 1985).

${ }^{11}$ I. J. R. Baumvol, F. C. Stedile, J.-J. Ganem, S. Rigo, and I. Trimaille, J. Electrochem. Soc. 142, 1205 (1995).

${ }^{12}$ E. P. Gusev, H. C. Lu, T. Gustafsson, and E. Garfunkel, Phys. Rev. B 52, 1759 (1995).

${ }^{13}$ J. P. Biersack, Nucl. Instrum. Methods Phys. Res. B 19, 32 (1987).

${ }^{14}$ J. B. Oude-Elferink, F. H. P. M. Habraken, W. F. van der Weg, E. Dooms, M. Heyns, and R. de Keersmaecker, Appl. Surf. Sci. 39, 219 (1989).

${ }^{15}$ I. J. R. Baumvol, F. C. Stedile, J.-J. Ganem, S. Rigo, and I. Trimaille, J. Electrochem. Soc. 143, 2938 (1996).

${ }^{16}$ P. J. Tobin, Y. Okada, S. A. Ajuria, V. Lakhotia, W. A. Feil, and R. Hedge, J. Appl. Phys. 75, 1811 (1994).

${ }^{17}$ R. Hedge, P. J. Tobin, K. G. Reid, B. Maiti, and S. A. Ajuria, Appl. Phys. Lett. 66, 896 (1997). 